\title{
Mixed-Metal Oxide Catalyst for Liquid Phase Benzene Alkylation
}

\author{
M. Alhassan ${ }^{1, *}$, U. Z. Faruq ${ }^{2}$ and A. Galadima ${ }^{3}$ \\ ${ }^{1}$ Sokoto State University, PMB 2134, Sokoto State, Nigeria \\ e-mail: mansuralhassan@gmail.com \\ ${ }^{2}$ Usmanu Danfodiyo University, PMB 2346, Sokoto, Nigeria \\ ${ }^{3}$ Federal University Gusau, PMB 1001, Zamfara State, Nigeria \\ ${ }^{*}$ Corresponding author
}

\section{Abstract}

Development of cheaper, active and more ecofriendly heterogeneous acid catalyst is a challenge mitigating the petrochemical industries. $\mathrm{CuO}-\mathrm{MoO}_{3} / \mathrm{ZrO}_{2}$ solid catalyst was prepared by impregnation using suitable precursor materials supported over zirconia. Upon calcination at $450^{\circ} \mathrm{C}$ for $2 \mathrm{~h}$ and activation (by soaking in $2 \mathrm{M} \mathrm{H}_{2} \mathrm{SO}_{4}$ for 30 minutes), available techniques were employed for the characterization. The available oxides and minerals in the catalyst were revealed by the XRF and XRD profiles respectively. The catalyst crystallite size (131.6nm) was obtained using the Bragg's equation from the latter. Thermal analysis showed three weight loss stages between $\left(49.25-152.06^{\circ} \mathrm{C}\right),\left(152.06-559.47^{\circ} \mathrm{C}\right)$ and $\left(559.47-752.0^{\circ} \mathrm{C}\right)$ while presence of sulphate and zirconia oxides was revealed by the FTIR analysis due to appearance of absorption bands around $1225-980 \mathrm{~cm}^{-1}$ and $700-600 \mathrm{~cm}^{-1}$ respectively. The catalyst $(1 \mathrm{wt} \%)$ was tested for alkylation in a continuous stirred reactor at $80^{\circ} \mathrm{C}$ using variable $(2: 1,4: 1$ and 10:1) benzene to 1-decene molar ratios. The effects of reaction time and molar ratios on the selectivity, conversion and yield were determined. The alkylation results showed that the catalyst is highly selective to 1-decylbenzene as low amount of side products was obtained. The product yield and conversion increased with reaction time and benzene /1decene molar ratio while selectivity decreased with increase in benzene /1-decene molar ratio with time.

\section{Received: July 3, 2019; Accepted: August 8, 2019}

Keywords and phrases: mixed metal oxide, heterogeneous catalyst, activity, selectivity, conversion.

Copyright (C) 2019 M. Alhassan et al. This is an open access article distributed under the Creative Commons Attribution License, which permits unrestricted use, distribution, and reproduction in any medium, provided the original work is properly cited. 


\section{Introduction}

The dependence of petrochemical industries on active, selective and cheap heterogeneous catalysts cannot be overemphasized. A catalyst is a chemical substance which, even in a minute quantity, affects the rate of a chemical reaction either positively or negatively without being appreciably consumed in the reaction (Petrov et al. [16], Galadima and Muraza [10]).

Homogeneous and heterogeneous catalysis are the broad categories which catalysis is divided into, and benzene alkylation has been carried out by both methods. While homogeneous catalysis deals with study of catalysts and reactants in the same phase, heterogeneous catalysis deals with reactants and catalysts in different phases (Mann and Saunders [15]). Homogeneous catalysts exist in the same (homogeneous phase) virtually almost always liquid phase. In heterogeneous catalysis, a solid catalyst is used for vapour or liquid phase reactions.

Depending on their uses, heterogeneous catalysts may be in the form of metals (skeletal metals), metal oxides, sulphides, heteropolyacids, nitrides, carbides, borides, alloys, molecular sieves, ceramics, fibres, wires, salts and mineral acids etc. (Smith and Notheisz [20], Galadima and Muraza [10], Gushchin et al. [11]).

The use of inorganic or mineral acid along with heterogeneous catalysts for liquid phase industrial reaction has become a focus. This is possible because there is ease in handling and product separation, catalyst re-use and minimization of wastes attributed to them. In addition, bimetallic supported catalysts are reported to be good catalysts for alkylation reactions (Wilson and Clark [22], Bolognini et al. [2]).

Alkylation is the reaction in which an alkyl (R-) group is added by means of substitution to an aromatic hydrocarbon. The unsaturated (or substituted) aryl or alkyl group usually added to the benzene ring (by substitution), could range from $C_{1}-C_{14}$. However, LABs (Linear Alkyl Benzenes) with alkyl or aryl groups within the range of $\mathrm{C}_{10}-\mathrm{C}_{14}$ are of rare use (Yuan et al. [23], Devassy et al. [6], Bordoloi et al. [3], Hernandez-Cortez et al. [13], Zhang et al. [24]).

Alkylation of benzene with olefins proceeds with a two-step mechanism via formation of a carbonium ion followed by attack on the benzene ring to form an alkyl benzene. The first step, involves the reaction of the olefin with the acid site to form an 
alkyl carbenium ion (which can isomerize almost immediately) to other carbenium ions by hydrogen transfer (Hernandez-Cortez et al. [13]).

\section{Experimental}

\section{Catalyst preparation}

The $\mathrm{CuO}-\mathrm{MoO}_{3} / \mathrm{ZrO}_{2}$ catalyst was prepared by the impregnation method as described by Haber et al. [12]. Aqueous saturated solution of ammonium heptamolybdate tetrahydrate $\left[\left(\mathrm{NH}_{4}\right)_{6} \mathrm{Mo}_{7} \mathrm{O}_{24} \cdot 4 \mathrm{H}_{2} \mathrm{O}\right]$ and copper nitrate $\left.\left[\mathrm{Cu}\left(\mathrm{NO}_{3}\right)_{2}\right)\right]$ was prepared by adding $15.75 \mathrm{~g}$ of each salt in a beaker containing $60 \mathrm{~cm}^{3}$ of distilled water. Zirconia (38.5g) was slowly deposited into the solution and then mixed at 120rpm for 1 h. The mixture was dried overnight in an oven at $105^{\circ} \mathrm{C}$.

The dried mass was calcined in a furnace at a temperature of $450^{\circ} \mathrm{C}$ for $2 \mathrm{~h}$.

To provide the required Brønsted acid sites that can catalyse the reaction, the calcined solid catalyst was soaked in $60 \mathrm{~cm}^{3}$ of $2 \mathrm{M}$ aqueous $\mathrm{H}_{2} \mathrm{SO}_{4}$ for 30 minutes. The catalyst was filtered and air dried for subsequent analysis.

\section{Characterization}

The XRD analysis was carried out using 5g of the catalyst on a PANalytical 2830 ZT XRD analyser. Two-Theta starting position was 4 degrees to 75 degrees with a twotheta step of 0.026261 at 8.67 seconds per step. The tube current was $40 \mathrm{~mA}$ and the tension was 45VA. Values of theta, d-spacing, 2 theta and peaks corresponding to ejected electrons are obtained. The crystallite size $(t)$ of the catalyst was established based on the XRD patterns using the relation:

$$
t=\frac{K \lambda}{B \cos \phi},
$$

where $t$ is crystallite size, $K$ is constant with values from 0.92 to $1.0, \lambda$ is wave length of the incident $x$-ray (usually taken as $0.1542 \mathrm{~nm}$ ), $B$ is full width at half maximum (FWHM) for the highest peak and must be converted to radians, using equation (2.2)

$$
B(\text { radians })=\frac{2 \Pi \times B}{360},
$$

where $\Pi=3.142, B$ is full width at half maximum (FWHM) for the highest peak. 
The IR spectra of the solid catalyst was obtained by grinding the catalyst into fine powder with a particle size about 1-2 microns. Seven milligram $(7 \mathrm{mg})$ of finely ground catalyst sample was placed on a $\mathrm{KBr}$ plate and a small drop of Nujol (mineral oil) was added. The sample was evenly distributed with the second $\mathrm{KBr}$ plate and placed in the sample holder which was scanned between $4000-400 \mathrm{~cm}^{-1}$ using an MB3000 IR analyzer and the spectra was generated using a high-tech Thermo Scientific Nicolet software.

Two milligrams ( $2 \mathrm{mg}$ ) of the ground samples of pulverized catalyst were placed into a sample cup. Elemental composition determination was carried out on a current of $14 \mathrm{kv}$ for major oxides and $20 \mathrm{kv}$ for the trace elements/rare earth metals. Selected filters were "kapton" for major oxides, Ag/Al-thin for the trace elements/rare earth metals. The spectra was developed using Horizon $\mathrm{MB}^{\circledR}$ XRF software. Each sample was measured for 100 seconds and the air medium was used throughout.

Thermal analysis was carried out using a DTG-60AH Thermogravimetric Analyser with the heating rate set at $20^{\circ} \mathrm{C} / \mathrm{min}$ and nitrogen flow rate $40 \mathrm{ml} / \mathrm{min}$ while the final heating temperature was $900^{\circ} \mathrm{C}$. The spectra was developed using a versatile Proteus ${ }^{\circledR}$ software while maintaining a cooling time of approximately 12 minutes.

\section{Catalyst evaluation}

Alkylation of benzene is an important process in the petrochemical industry. One of the most useful alkyl benzenes, ethylbenzene (EB), is used as feedstock in the production of styrene, polystyrene etc. with higher olefins/substituted alkanes $\left(\mathrm{C}_{10}-\mathrm{C}_{14}\right)$, linear alkyl benzenes (LABs), which are the primary raw materials for the synthesis of lab sulfonates and surfactant intermediates used in producing detergents, are produced (Devassy et al. [6], Hernandez-Cortez et al. [13], Zhang et al. [24]).

Liquid phase alkylation reaction is of great industrial use. Although benzene alkylation could be carried out within temperature range of $70-180^{\circ} \mathrm{C}$ and far above as reported, Yuan et al. [23] established that at $80^{\circ} \mathrm{C}$, there is an improved selectivity (>26.0) and conversion (98.4\%) of 1-dodecene. The reaction was reported to have been achieved through variable reaction conditions. The main catalysts used to achieve this reaction are the Lewis acids, like $\mathrm{AlCl}_{3}, \mathrm{FeBr}_{3}$ etc. at about $900^{\circ} \mathrm{C}$ and $1 \mathrm{~atm}$. However, a temperature of $300^{\circ} \mathrm{C}$ has been reported elsewhere in the alkylation of m-cresol (Bolognini et al. [2], Khlebnikova et al. [14]). 
Three sets of alkylation reactions were carried out; using 2:1, 4:1 and 10:1 benzenedec-1-ene molar ratios. 2:1 molar ratio consisted of pure benzene $\left(18 \mathrm{~cm}^{3}\right), 0.03 \mathrm{~g}(1 \mathrm{wt} \%)$ of the prepared catalyst and $19 \mathrm{~cm}^{3}$ of 1-decene. $4: 1$ molar ratio contained $36 \mathrm{~cm}^{3}$ of benzene, $19 \mathrm{~cm}^{3}$ of 1 -decene and $0.045 \mathrm{~g}(1 \mathrm{wt} \%)$ of the solid catalyst while 10:1 consisted of $90 \mathrm{~cm}^{3}$ of benzene, $19 \mathrm{~cm}^{3}$ of 1 -decene and $0.092 \mathrm{~g}(1 \mathrm{wt} \%)$ of the catalyst. The set up was maintained and refluxed for $2 \mathrm{~h}$ reaction time, taking a fraction of the products every 40 minutes.

\section{Product analyses and selectivity properties determination}

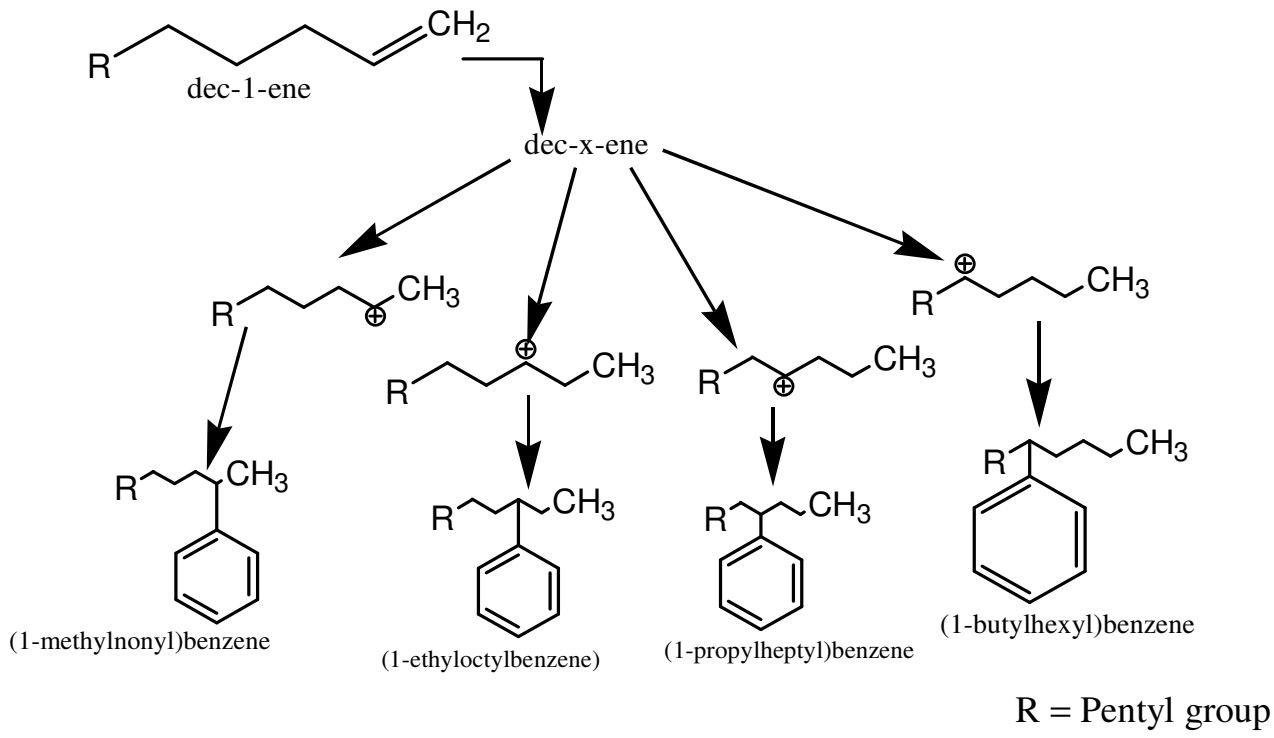

Figure 1. Possible obtainable alkylation products from benzene alkylation with 1-decene. Source: Hernandez-Cortez et al. [13].

Agilent 7890A GC coupled with 5977MS was used for the analysis of the alkylation products in the variable fractions. $1 \mu 1$ of the sample was punctured through the inlet using an automatic sampling device. As the sample pass through the column (located in a temperature-controlled oven), equipped with an HP-5 capillary column $(30 \mathrm{~m} \times 0.25 \mathrm{~mm}$ i.d) with a coating of $0.25 \mu \mathrm{m}$ thick to the detector, the $\mathrm{GC}$ was temperature-programmed from $50^{\circ} \mathrm{C}$ to $300^{\circ} \mathrm{C}$ at $5^{\circ} \mathrm{C} / \mathrm{min}$ held at final temperature for 20 minutes with hydrogen as the carrier gas with a flow rate of $1 \mathrm{ml} / \mathrm{min}$, pressure of $50 \mathrm{kPa}$. Representative peaks matching the available compounds were generated by Agilent ChemStation software. 
The moles of limiting reactant and that of the target product of the reaction were used to determine the yield, as presented in equation (3) (Yuan et al. [23]).

$$
\% \text { yield }=\frac{\text { Moles of target product }}{\text { Moles of limiting Reactant }} \times 100 \text {. }
$$

The percentage conversion was obtained by using the equation (4) (Yuan et al. [23]).

$$
=\frac{\text { Initial moles of limiting reactant }- \text { Moles of limiting reactant consumed }}{\text { Initial moles of limiting reactant }} \times 100 \text {. }
$$

The selectivity is the ability of the catalyst to cause, direct or favor the formation of one product in a process where several others are possible. It was obtained using the equation (5) (Yuan et al. [23]).

$$
\text { selectivity }=\frac{\text { Moles of target product }}{\text { Moles of total products }} \times 100 \text {. }
$$

\section{Results}

The results obtained from catalyst characterization and testing are presented in the following Tables 1-6 and Figures 1-5.

Table 1. Results of XRD analysis of the $\mathrm{CuO}-\mathrm{MoO}_{3} / \mathrm{ZrO}_{2}$ catalyst.

\begin{tabular}{lcc}
\hline Mineral & Chemical Formula & Composition (\%) \\
\hline Baddeletite & $\mathrm{Zr}_{4} \mathrm{O}_{8}$ & 42 \\
Bonnatite & $\mathrm{Cu}_{4} \mathrm{~S}_{4} \mathrm{O}_{28} \mathrm{H}_{24}$ & 58 \\
\hline
\end{tabular}

Table 2. Absorption peaks obtained from FTIR spectra of the $\mathrm{CuO}-\mathrm{MoO}_{3} / \mathrm{ZrO}_{2}$.

\begin{tabular}{ccc}
\hline Absorption range $\left(\mathbf{c m}^{\mathbf{- 1}}\right)$ & Peak description & Functional group \\
\hline $3200-3600$ & Broad, intense & $-\mathrm{OH}$ \\
$2700-2900$ & Medium & C-H stretch \\
$1225-980$ & Medium & S-O \\
$700-600$ & Medium & Zr-O \\
\hline
\end{tabular}


Table 3. TGA results of the $\mathrm{CuO}-\mathrm{MoO}_{3} / \mathrm{ZrO}_{2}$ catalyst.

\begin{tabular}{lcc}
\hline Temperature range $\left({ }^{\circ} \mathbf{C}\right)$ & Weight loss $(\mathbf{m g})$ & Weight loss $(\%)$ \\
\hline $43-152$ & 3.59 & 55 \\
$152-560$ & 0.77 & 11.8 \\
$560-752$ & 2.17 & 33.2 \\
\hline
\end{tabular}

Table 4. The results of XRF analysis of the $\mathrm{CuO}-\mathrm{MoO}_{3} / \mathrm{ZrO}_{2}$ catalyst.

\begin{tabular}{cc}
\hline Oxide Composition & \% Abundance \\
\hline $\mathrm{P}_{2} \mathrm{O}_{5}$ & 9.90 \\
$\mathrm{SO}_{3}$ & 11.00 \\
$\mathrm{TiO}_{2}$ & 0.04 \\
$\mathrm{Fe}_{2} \mathrm{O}_{3}$ & 0.046 \\
$\mathrm{Co}_{3} \mathrm{O}_{4}$ & 0.007 \\
$\mathrm{CuO}$ & 12.93 \\
$\mathrm{As}_{2} \mathrm{O}_{3}$ & 0.034 \\
$\mathrm{ZrO}_{2}$ & 50.91 \\
$\mathrm{BaO}$ & 0.14 \\
$\mathrm{CeO}_{2}$ & 0.02 \\
$\mathrm{~Tb}_{4} \mathrm{O}_{7}$ & 0.03 \\
$\mathrm{Er}_{2} \mathrm{O}_{3}$ & 0.03 \\
$\mathrm{PtO}_{2}$ & 0.091 \\
$\mathrm{PbO}$ & 0.029 \\
$\mathrm{Bi}_{2} \mathrm{O}_{3}$ & 0.022 \\
$\mathrm{~L} \mathrm{O}_{\mathrm{I}}$ & 14.22 \\
\hline
\end{tabular}

L.O.I $=$ Loss on ignition. 
Table 5. Alkylation products obtained using 2:1, 4:1 and 10:1 molar ratios.

\begin{tabular}{lcccccc}
\hline $\begin{array}{l}\text { Reaction } \\
\text { time } \\
(\min )\end{array}$ & $\mathbf{2 : 1}$ & $\mathbf{4 : 1}$ & $\mathbf{1 0 : 1}$ & $\mathbf{2 : 1}$ & $\mathbf{4 : 1}$ & $\mathbf{1 0 : 1}$ \\
\cline { 2 - 7 } & 13.19 & 18.77 & 32.91 & $* 11.93$ & $* 14.75$ & $* 32.23$ \\
\hline 40 & 31.03 & 37.91 & 58.41 & $* 20.25$ & $* 12.57$ & $* 11.09$ \\
80 & 51.22 & 39.81 & 68.54 & $* 10.23$ & $* 21.85$ & $* 20.83$ \\
120 & & &
\end{tabular}

*Other products (that appeared) in all molar ratios with time are:

10:1- Hexadecane, Toluene, 1-octene, Nonadecane, Eicosane, Heneicosane and Undecylbenzene.

4:1- Hexadecane, 2-octene, Eicosane, Octadecane, Heneicosane, Heptacosane, 4-decene and 5-undecene.

2:1- Hexadecane, 1-octene, 4-undecene, 2-undecene, 4-decene, 2-octene, 1-decene.

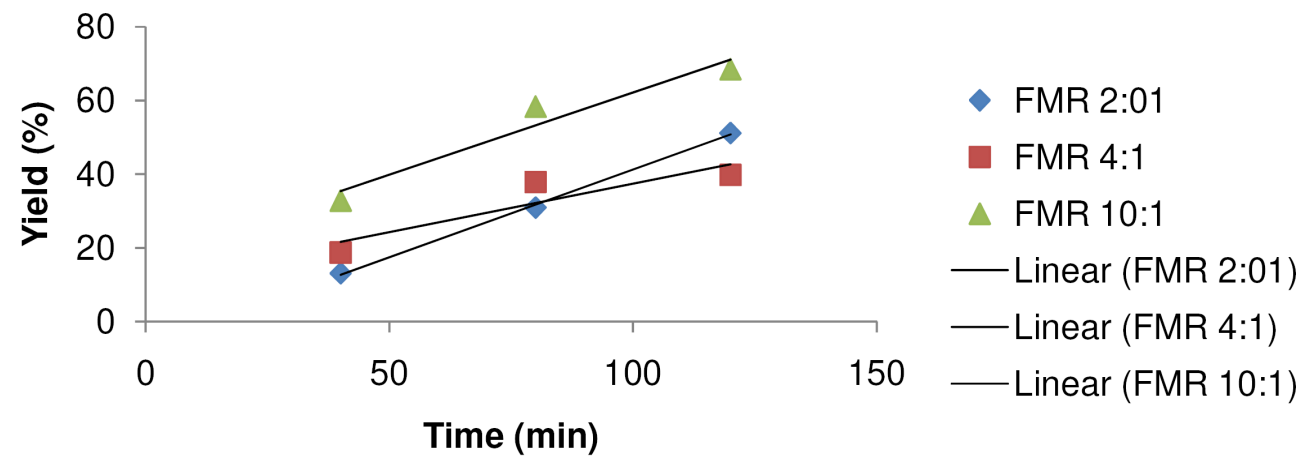

Figure 2. Graph showing variation in $\%$ decyl benzene and change in substrate molar ratio with time.

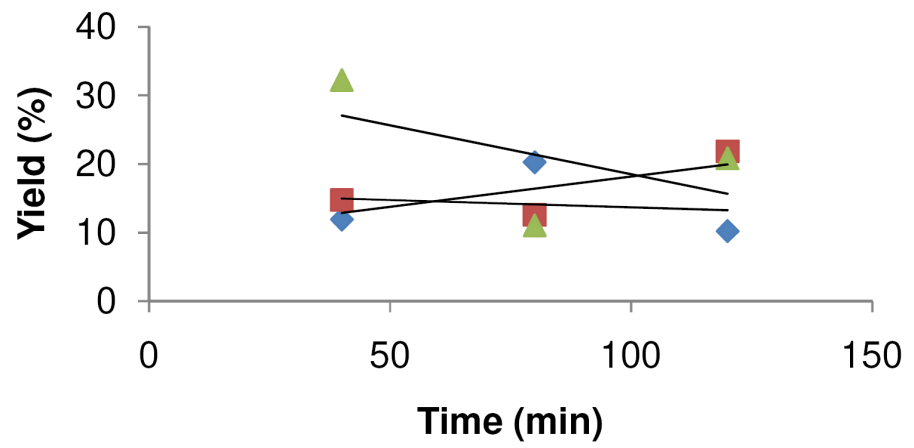

$\checkmark$ FMR 2:01

- FMR 4:1

$\triangle$ FMR 10:1

- Linear (FMR 2:01)

- Linear (FMR 4:1)

— Linear (FMR 10:1)

Figure 3. Graph showing variation in $\%$ other products and change in substrate molar ratio with time. 


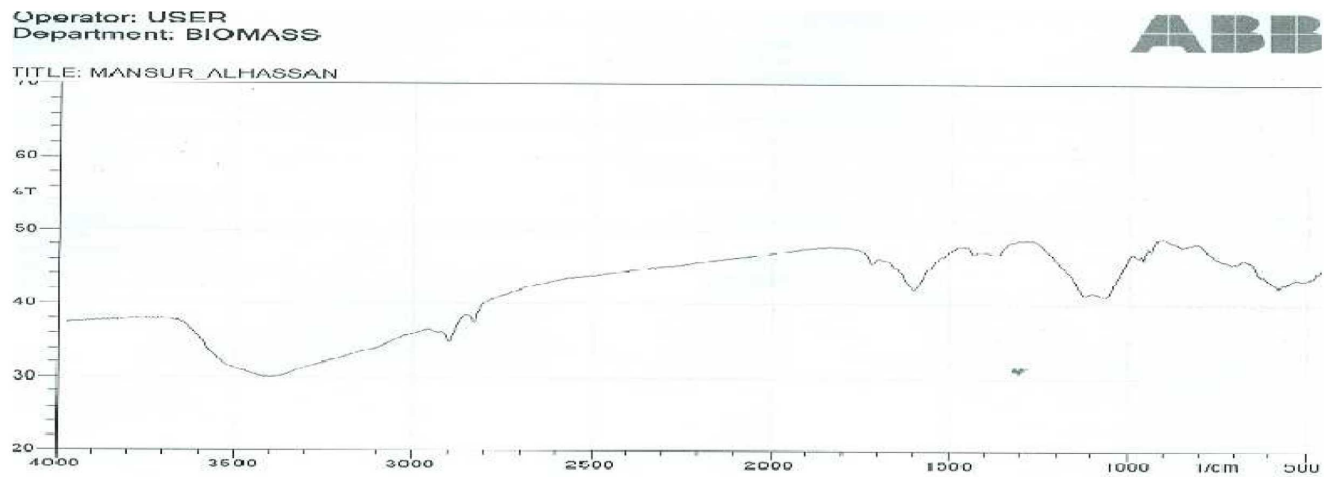

-abels of MANSUR_AIHASSAN:

Figure 4. FTIR spectra of the $\mathrm{CuO}-\mathrm{MoO}_{3} / \mathrm{ZrO}_{2}$ catalyst.

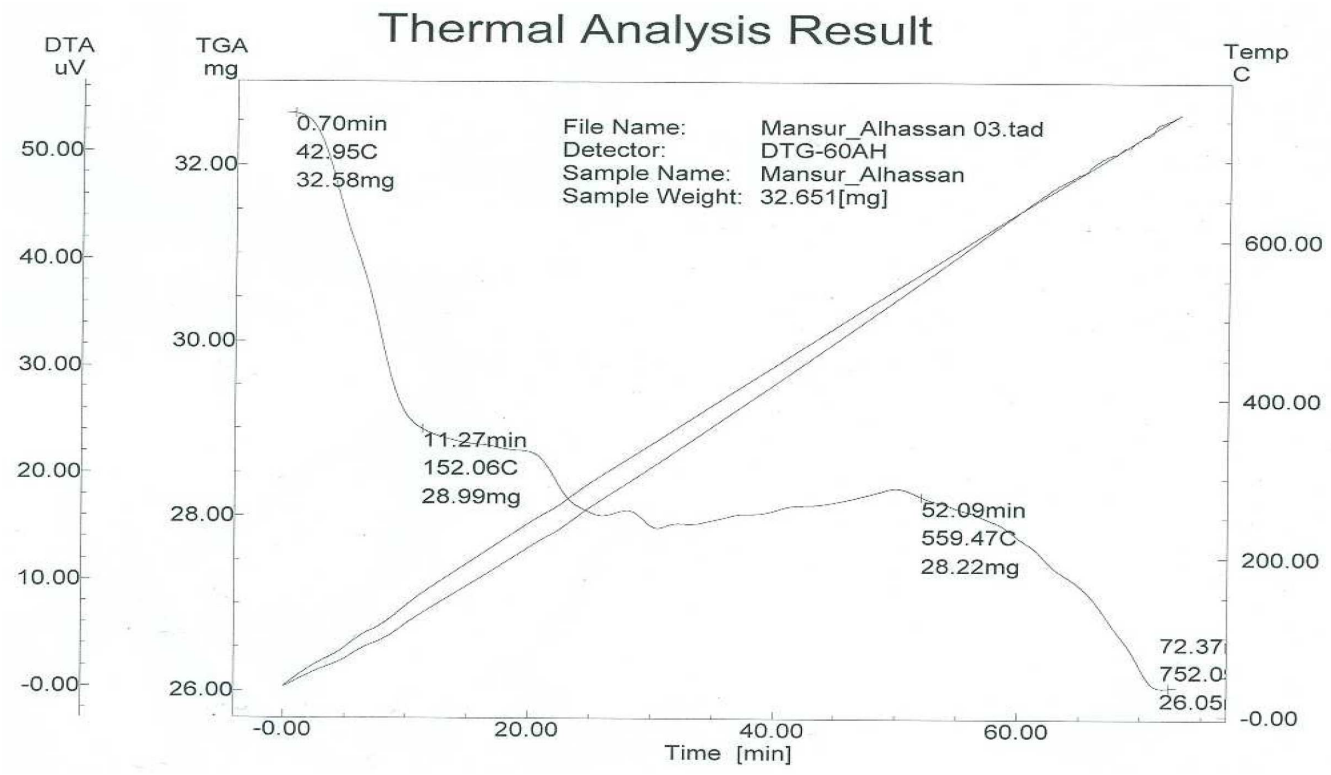

Figure 5. TGA spectra of the $\mathrm{CuO}-\mathrm{MoO}_{3} / \mathrm{ZrO}{ }_{2}$ catalyst. 
Table 6. Percentage selectivity, yield and conversion in the different alkylation products with time.

\begin{tabular}{clccc}
\hline Molar ratio & Catalyst Testing & \multicolumn{3}{c}{ Reaction time (minutes) } \\
\cline { 3 - 5 } & & $\mathbf{4 0}$ & $\mathbf{8 0}$ & $\mathbf{1 2 0}$ \\
\hline \multirow{3}{*}{$\mathbf{2 : 1}$} & Selectivity (\%) & 52.50 & 60.50 & 83.35 \\
& Yield (\%) & 13.19 & 31.03 & 51.22 \\
& Conversion (\%) & 25.12 & 51.29 & 61.45 \\
& Selectivity (\%) & 55.99 & 75.09 & 64.56 \\
\multirow{2}{*}{ 4:1 } & Yield (\%) & 18.77 & 37.91 & 39.81 \\
& Conversion (\%) & 33.52 & 50.48 & 61.66 \\
& Selectivity (\%) & 60.09 & 84.04 & 76.69 \\
$\mathbf{1 0 : 1}$ & Yield (\%) & 32.91 & 58.41 & 68.54 \\
& Conversion (\%) & 54.76 & 69.50 & 89.37 \\
\hline
\end{tabular}

\section{Discussion}

The result of XRD analysis of the prepared catalyst presented in Table 1 indicated the presence of two principal minerals; Baddeleyite (42\%) and Bonattite (58\%). Baddeleyite $\left(\mathrm{Zr}_{4} \mathrm{O}_{8}\right)$ is equivalent to $\mathrm{ZrO}_{2}$, the catalyst support material while Bonattite $\left(\mathrm{Cu}_{4} \mathrm{~S}_{4} \mathrm{O}_{28} \mathrm{H}_{24}\right)$ is equivalent to $\mathrm{CuSO}_{4} \cdot 12 \mathrm{H}_{2} \mathrm{O}$. The principal mineral components in the catalyst precursor are $\mathrm{ZrO}_{2}$ (as shown in Tables 1 and 4) and hydrated copper sulphate $\left(\mathrm{CuSO}_{4} \cdot 3 \mathrm{H}_{2} \mathrm{O}\right)$; constituting up to $42 \%$ of the solid catalyst; which agrees with Zhang et al. [24] that up to $40 \mathrm{wt} \%$ of the support can be employed.

Although after calcination at $450^{\circ} \mathrm{C}$, moisture due to physisorbed water is removed from the catalyst, the XRD analysis showed up to 12 moles of water. The calcined catalyst might absorb some moisture after cooling prior to the XRD analysis and possibly some remnant of water of crystallization. According to Haber et al. [12], surfaces of solid heterogeneous catalysts could be blocked by physisorbed water. Zhang and co-workers [24] and Yuan et al. [23] reported that fraction of water of crystallization could be noticed even after calcination. The presence of copper sulphate mineral (bonatite) is attributed to the precursor salt, copper nitrate $\mathrm{Cu}\left(\mathrm{NO}_{3}\right)_{2}$ while sulphate species comes from the sulphuric acid acidification process in the catalyst activation 
There were no traces of molybdenum reported in the XRD results of the prepared $\mathrm{CuO}-\mathrm{MoO}_{3} / \mathrm{ZrO}_{2}$ catalyst. It could be that the molybdenum phase is either washed away during preparation process along with excess water or decomposed during calcination or heat treatment processes.

The crystallite size (t) of the catalyst was determined to be $131.6 \mathrm{~nm}$ which was much greater than size of $<2 \mathrm{~nm}$ (diameter) reported by Devassy and co-workers [6] for zirconia-supported 12-tungstophosphoric acid utilized as solid catalyst for the synthesis of linear alkyl benzenes. However, Zhang et al. [24] reported that upon calcination, diffractions shifts to higher angles with reduced intensities leading to an increased crystallinity. The large crystallite size could possibly be due to the absence of molybdenum.

Table 2 (and Figure 4) presents result of FTIR analysis of the $\mathrm{CuO}-\mathrm{MoO}_{3} / \mathrm{ZrO}_{2}$ catalyst. Showing the peaks corresponding to the available oxides in the catalyst. The mild absorption peak that appeared around $\left(700-600 \mathrm{~cm}^{-1}\right)$ was due to $\mathrm{Zr}-\mathrm{O}$ bond confirming the presence of $\mathrm{ZrO}_{2}$ which agrees with the XRD spectra that showed an abundance of $42 \%$.

Presence of sulphate species was confirmed by the appearance of S-O absorption around $\left(1225-980 \mathrm{~cm}^{-1}\right)$. This further testified the sulphuric acid acidification in the catalyst activation process. The broad peak that appeared between $3200-3600 \mathrm{~cm}^{-1}$ and (3000-2800 $\mathrm{cm}^{-1}$ ) could be attributed to hydrogen bonded hydroxyl groups and physisorbed or crystallization water molecules. This was responsible for the presence of water molecules in the catalyst as indicated by the XRD profile. Devassy and co-workers [6] reported similar results for zirconia supported 12-tungstophosphoric acid as a solid catalyst for the synthesis of linear alkyl benzenes. $\mathrm{Cu}-\mathrm{O}$ bond is IR inactive hence, no peak could be attributed to its presence. The stretching related to the $\mathrm{Cu}-\mathrm{O}$ bonds are located at frequencies below $400 \mathrm{~cm}^{-1}$ (Baran [1]). The FTIR spectra corroborated the absence of Mo-O absorption band which should have appeared around $998 \mathrm{~cm}^{-1}$. Hardcastle and Wachs [9] assigned stretching frequencies and bond distances in tetrahedrally coordinated molybdenum oxide reference compounds between 998$280 \mathrm{~cm}^{-1}$. 
The thermogravimetric analysis (thermal evolution) result of the $\mathrm{CuO}-\mathrm{MoO}_{3} / \mathrm{ZrO}_{2}$ catalyst (presented in Table 3 and Figure 5) showed that the first weight loss stage occurred within temperature range of $42.95^{\circ} \mathrm{C}$ to $152.06^{\circ} \mathrm{C}$ and accounted for $55 \%$ weight loss. The second occurred between $152.06^{\circ} \mathrm{C}$ to $559.47^{\circ} \mathrm{C}$ while the third occurred between $559.47^{\circ} \mathrm{C}$ to $752.0^{\circ} \mathrm{C}$ and accounted for $11.8 \%$ and $33.2 \%$ respectively. The volatile components in the solid catalyst like $\mathrm{NH}_{3}$ and $\mathrm{NO}_{2}$ have decomposed during the calcination process which was carried out at $450^{\circ} \mathrm{C}$ for $2 \mathrm{~h}$. Carbonate and acetate ions that did not completely decompose during calcination perhaps contributed to the weight loss recorded in the TGA analysis. The first and second weight loss stages were due to evaporation of $66.8 \%$ physisorbed water, other carbonates and acetates while the third weight loss stage accounted for $33.7 \%$ water of crystallization.

The percentage moisture in $\mathrm{CuSO}_{4} \cdot 12 \mathrm{H}_{2} \mathrm{O}$ (bonattite) was approximately $57.5 \%$ and the TGA spectra (Figure 5) indicated a significant weight loss between room temperature to 100 or $125^{\circ} \mathrm{C}$ within which all absorbed water would evaporate. Hernandez-Cortez and co-workers [13] outlined that in solid samples; the first weight loss stage occurring from room temperature to about $152^{\circ} \mathrm{C}$ was due to physisorbed water and accounted for 55 weight loss $(\%)$. The mass loss between $152^{\circ} \mathrm{C}$ to $752^{\circ} \mathrm{C}$ was attributed to loss of water molecules due to crystallization and accounted for $11.8 \%$. Wan and Davis [21] reported $1.9 \mathrm{wt} \%$ water loss for a heterogeneous catalyst used for naproxen asymmetric synthesis.

Table 4 presented the results for XRF analysis of the solid $\mathrm{CuO}-\mathrm{MoO}_{3} / \mathrm{ZrO}_{2}$ catalyst. The principal oxide $\left(\mathrm{ZrO}_{2}\right)$, with the support constituting $50.91 \%$ of the total oxides in the catalyst. This is in agreement with the suggestion of Zhang et al. [24] that support materials could be up to $>40 \mathrm{wt} \%$ of a solid heterogeneous catalyst. $\mathrm{CuO}, \mathrm{SO}_{3}$ and $\mathrm{P}_{2} \mathrm{O}_{5}$ are the next dominant oxides with $12.93 \%, 11.00 \%$ and $9.90 \%$ abundance respectively. Trace amount of $\mathrm{As}_{2} \mathrm{O}_{3}, \mathrm{PtO}_{2}, \mathrm{Bi}_{2} \mathrm{O}_{3}, \mathrm{PbO}, \mathrm{Er}_{2} \mathrm{O}_{3}, \mathrm{~Tb}_{4} \mathrm{O}_{7}, \mathrm{Co}_{3} \mathrm{O}_{4}, \mathrm{TiO}_{2}$ and $\mathrm{CeO}_{2}$ were also discovered. Compounds lost on ignition (L.O.I) amounted to $14.22 \%$ (second most dominant, next to $\mathrm{ZrO}_{2}$ ). Most components of the LOI may range from physisorbed water, water of crystallization or water originating from acidic protons as reported by Devassy et al. [6]. The disappearance of molybdenum or any of its oxides in the XRF results of the catalyst just like in the XRD, further justifies the absence of 
molybdenum in the prepared solid catalyst. Haber et al. [12] reported in the manual of methods and procedure for catalyst preparation and characterization that, during processes of catalyst preparation, important active components may be loss due to washing, drying or calcination of impregnated precursor. The absence therefore justifies that molybdenum oxide has been lost from the preparation process, which was only noticed at the point of characterization. Therefore it can be concluded that the prepared catalyst was $\mathrm{CuO} / \mathrm{ZrO}_{2}$.

Traces of metal oxides like $\mathrm{As}_{2} \mathrm{O}_{3}, \mathrm{PtO}_{2}, \mathrm{Bi}_{2} \mathrm{O}_{3}, \mathrm{PbO}, \mathrm{Er}_{2} \mathrm{O}_{3}, \mathrm{~Tb}_{4} \mathrm{O}_{7}, \mathrm{Co}_{3} \mathrm{O}_{4}, \mathrm{TiO}_{2}$ and $\mathrm{CeO}_{2}$ that appeared in the XRF result could be attributed to impurities in the zirconia.

Table 5 depicts the variation with time, of percentage decyl benzene and other side products realized from the 2:1, 4:1 and 10:1 benzene to 1-decene molar ratio. There is an observable increase in the quantity of decyl benzene realized with time. The $\%$ yield for decyl benzene increased from $13.19 \%$ to $51.22 \%$ at 40 and 120 minutes respectively. There is an observable increase as well, in the available side products from 40 minutes to 80 minutes. This clearly indicated the effect of residence time as reported by Yuan et al. [23] that at reaction time, an increase in yield and selectivity is generally observed. However, the final conversion decreases with increase in temperature. Saxena et al. [18] reported the highest conversion of $86.6 \%$ on alkylating benzene with zeolite-based catalyst and concluded that increase in reaction temperature could not enhance product conversion.

The percentage decyl benzene obtained at 40 minutes $(18.77 \%$ ) increased to $37.91 \%$ at 80 minutes which increased slightly to $39.81 \%$ at 120 minutes. As compared to the percentage products realized using 2:1 (Table 5), percentage decyl benzene increased from $13.19 \%$ (2:1, 40 minutes) to $18.77 \%$ (4:1, 80 minutes). Also, $31.03 \%$ (2:1, 80 minutes) shooted up to $37.91 \%$ (4:1, 80 minutes) while $51.22 \%(2: 1)$ decreased to $39.81 \%(4: 1)$ at 120 minutes. This shows that the reaction gives better yield at lower molar ratio and longer reaction time. A contrary report by Yuan et al. [23] showed that conversion for 1-decene increases with increase in benzene content in the reactant mixture. However, the decrease in percentage decyl benzene (39.81\%) observed in 4:1 at 120 minutes compared to $51.22 \%$ in $2: 1,120$ minutes could be attributed to the higher catalytic activity at the beginning of reactions which decreases gradually with time. The 
same reason has been reported by Yuan et al. [23], Faghihian and Mohammadi [8], Zhang et al. [24] and Khlebnikova et al. [14]. It could similarly be observed that, there was an increase in the product (decylbenzene) yield with time. Gushchin et al. [11] reported a yield of $88.11 \%$ at 30 minutes, which decreased to $60.06 \%$ at $5 \mathrm{~h}$ reaction time in the alkylation of benzene using dimethyldichlorosilane.

Product yield at 80 minutes $(31.03 \%)$ in $2: 1$ increased to $37.91 \%$ in $4: 1,80$ minutes; but $51.22 \%$ observed at 120 minutes in $2: 1$ decreased to $39.81 \%$ in $4: 1,120$ minutes.

Table 5 (and Figure 2) presents the alkylation results obtained for 10:1 benzene to alkene molar ratios at 40, 80 and 120 minutes reaction time. The percentage decyl benzene realized at 40 minutes (32.91\%) shooted up to $58.41 \%$ at 80 minutes and further to $68.54 \%$ at 120 minutes. As compared to alkylation products obtained using 2:1 and 4:1 benzene to 1-decene molar ratios, the percentage decyl benzene obtained using 10:1 molar ratio at 40, 80 and 120 are higher. Decyl benzene (product) yield at 40 minutes increased from $13.19 \%(2: 1)$ to $18.77 \%$ (4:1) and further to $32.91 \%(10: 1)$. The product yield $(32.91 \%)$ observed in 10:1 (40 minutes) nearly doubles $18.77 \%$ obtained for $4: 1$ (40 minutes) showing a multiple increase in yield with increase in reactants molar ratio. This is further observed in product yield at 80 minutes from $31.03 \%$ (2:1) to $37.91 \%$ (4:1) and further to $58.41 \%$ (10:1). It has been reported by Yuan et al. [23], Ebrahimi et al. [7], Zhang et al. [24], Faghihian and Mohammadi [8] and Devassy et al. [6], that, higher benzene to alkene molar ratios favours product yield. Faghihian and Mohammadi [8] reported this as the reason why industries use high (8.75:1) benzene to alkene molar ratios for alkyl benzene productions. Similarly, the percentage side products (Table 5 and Figure 3) obtained in the reactions at 40 minutes increased from $11.93 \%$ (2:1) to $14.75 \%(4: 1)$ and further to $32.23 \%$ (10:1) followed this trend. In addition, the decrease in the percentage side products at 80 minutes from $20.25 \%$ (2:1) to $12.57 \%$ (4:1) to $11.09 \%$ (10:1) indicates a decrease in side products with increase in benzene molar ratio in alkylation reactions. Zhang et al. [24], Faghihian and Mohammadi [8], Devassy et al. [6] and Guschin et al. [11] reported that excess molar of benzene over olefin could be used to reduce the amount of dialkylated products.

The increase in yield with increase in benzene to 1-decene molar ratios; the increase in product yield with residence time and the decrease in catalyst activity with time are outlined from the above statements.

The calculated percentage selectivity, yield and conversion obtained for the various 
benzene to1-decene molar ratios at 40,80 and 120 minutes is presented in Table 6 . The selectivity for 1-decene using 2:1 (benzene to 1-decene) molar ratios increased from $52.5 \%$ (40 minutes) to $60.5 \%$ ( 80 minutes) which further shooted up to $83.35 \%$ (120 minutes). This clearly indicated that selectivity is favoured by increase in residence time as reported by Faghihian and Mohammadi [8], Saxena et al. [18] that increase in selectivity is noticed with increase in reaction time.

At 4:1 benzene/1-decene molar ratios, the selectivity shifted from 55.99\% (40 minutes) to $75.09 \%$ (80 minutes). However, at 120 minutes, it decreased to $64.56 \%$. The increased selectivity from $55.99 \%$ to $75.09 \%$ at 40 and 80 minutes respectively, could be attributed to the difference in the residence time. On the other hand, the selectivity in $4: 1$ benzene /1-decene molar ratio decreased from 75.09\% (80 minutes) to 64.56\% (120 minutes) shows a decrease in selectivity at high molar ratios with time. Yuan and coworkers [23] reported a decrease in selectivity $(26.0 \%-22.6 \%)$ at high molar ratios.

At 10:1 benzene/1-decene molar ratios, the selectivity increased from $60.09 \%$ (40 minutes) to $84.04 \%$ ( 80 minutes) but decreased to $76.69 \%$ (120 minutes). This further confirms the decrease in selectivity with time at high reactant ratios.

The product selectivity at 40 minutes increased from $52.5 \%$ (2:1) to $55.99 \%$ (4:1) and further to $60.09 \%$ (10:1). This shows the effect of increased selectivity with increase in benzene/1-decene molar ratios. The selectivity for decyl benzene in all molar ratios increased with increase in benzene / 1-decene molar ratios but decreased with time at higher molar ratios. The selectivity for decylbenzene in all the molar ratios increased with increase in benzene-alkene molar ratios except in 4:1, 80 minutes $(75.09 \%)$ which decreased to $(64.56 \%)$ at 120 minutes and $10: 1$, further at 80 minutes $(84.04 \%)$ which also decreased to $(76.69 \%)$ at 120 minutes. An effect of benzene-alkene molar ratio plays a significant role in alkylation reaction. The highest selectivity observed for 10:1 ( 80 minutes) is $84.04 \%$ which is much higher than $26.0 \%$ (selectivity) reported for USY zeolite for alkylation of benzene with 1-Dodecene by Yuan et al. [23]. The difference in residence time and reactant molar ratios could account for this, as reported by Yuan et al. [23], Faghihian and Mohammadi [8] and Gushchin et al. [11].

The product selectivity at 120 minutes for 2:1 (83.35\%) was higher than $64.56 \%$ (4:1, 120 minutes) and $76.69 \%$ (10:1, 120 minutes) showing a decrease in selectivity at higher molar ratios. Yuan and co-workers [23] reported a decrease in selectivity for USY zeolite catalyst (26.0\%-22.6\%) at higher molar ratios. According to Galadima and 
Muraza [10], Gushchin et al. [11], increase in benzene to alkene molar ratio promotes catalyst selectivity to both mono- and dialkylated benzenes when the temperature and space velocity are kept constant.

\section{Conclusion}

The prepared solid catalyst $\left(\mathrm{CuO} / \mathrm{ZrO}_{2}\right)$ was found active, selective and gave desired products along with some by-products. In addition, benzene to alkene molar ratios has positive effects on product yield, conversion and selectivity for alkyl benzene. Highest conversion of $89.37 \%$, selectivity of $84.04 \%$ and yield of $68.54 \%$ were obtained.

Furthermore, reaction residence time increases the product yield, conversion and selectivity of alkylation reaction. Reaction is still on going to explore new parameters such as catalyst lifetime, optimal performance and deactivation properties for process upgrade.

\section{References}

[1] Enrique J. Baran, Structural data and vibrational spectra of the copper(II) complex of Lselenomethionine, Zeitschrift für Naturforschung B 60 (2005), 663-666. https://doi.org/10.1515/znb-2005-0609

[2] M. Bolognini, F. Cavani, D. Scagliarini, C. Flego, C. Perego and M. Saba, Heterogeneous basic catalysts as alternative to homogeneous catalysts: reactivity of $\mathrm{Mg} / \mathrm{Al}$ mixed oxides in the alkylation of $m$-cresol with methanol, Catalysis Today 75 (2002), 103-111. https://doi.org/10.1016/S0920-5861(02)00050-0

[3] A. Bordoloi, Biju M. Devassy, P. S. Niphadkar, P. N. Joshi and S. B. Halligudi, Shape selective synthesis of long-chain linear alkyl benzene (LAB) with AlMCM-41/Beta zeolite composite catalyst, Journal of Molecular Catalysis A: Chemical 253 (2006), 239244. https://doi.org/10.1016/j.molcata.2006.03.045

[4] M. Che, O. Clause and C. Marcilly, Impregnation and ion exchange, in: J. Weitkamp, ed., Handbook of Heterogeneous Catalysis, Vol. 1, Wiley-VCH, Weinheim, 1997, pp. 191211.

[5] B. H. Davis, Handbook of Heterogeneous Catalysis, G. Ertl, H. Knozinger and J. Weitkamp, John Wiley-VCH, New York, NY, 1997, pp. 13-23.

[6] M. B. Devassy, F. Lefebvre and S. B. Halligudi, Zirconia-supported 12tungstophosphoric acid as a solid catalyst for the linear alkyl benzenes, Journal of 
Catalysis 231 (2005), 1-10. https://doi.org/10.1016/j.jcat.2004.09.024

[7] A. Nejad Ebrahimi, A. Z. Sharak, S. A. Mousavi, F. Aghazadeh and Ahmad Soltani, Modification and optimization of benzene alkylation process for production of ethylbenzene, Chemical Engineering and Processing 50 (2011), 31-36. https://doi.org/10.1016/j.cep.2010.10.011

[8] H. Faghihian and M. H. Mohammadi, Acid activation effect on the catalytic performance of Al-pillared bentonite in alkylation of benzene with olefins, Applied Clay Science 93-94 (2014), 1-7. https://doi.org/10.1016/j.clay.2014.02.026

[9] Franklin D. Hardcastle and Israel E. Wachs, Determination of molybdenum-oxygen bond distances and orders by Raman spectroscopy, Journal of Raman Spectroscopy 21 (1990), 683-691. https://doi.org/10.1002/jrs.1250211009

[10] A. Galadima and O. Muraza, Role of zeolite catalysts for benzene removal from gasoline via alkylation; A review, Microporous and Mesoporous Materials 213 (2015), 169-180. https://doi.org/10.1016/j.micromeso.2015.02.029

[11] P. A. Gushchin, I. M. Kolesnikov, V. A. Vinokurov, E. V. Ivanov, V. A. Lyubimenko and V. N. Borshch, Alkylation of Benzene with ethylene in the presence of dimethyldichlorosilane Journal of Catalysis 352 (2017), 75-82. https://doi.org/10.1016/j.jcat.2017.05.004

[12] J. Haber, J. H. Block and B. Delmon, Manual of methods and procedures for catalyst characterization (Technical Report), Pure and Applied Chemistry 67(8-9) (1995), 12571306. https://doi.org/10.1351/pac199567081257

[13] J. G. Hernandez-Cortez, L. Martinez, L. Soto, A. Lopez, J. Navarrete, Ma. Manriquez, V. H. Lara and E. Lopez-Salinas, Liquid phase alkylation of benzene with dec-1-ene catalyzed on supported 12-tungstophosphoric acid, Catalysis Today 150 (2010), 346-352. https://doi.org/10.1016/j.cattod.2009.12.003

[14] E. Khlebnikova, E. Ivashkina and I. Dolganova, Benzene alkylation with ethylene: the way to increase the process efficiency, Chemical Engineering and Processing 120 (2017), 234-240. https://doi.org/10.1016/j.cep.2017.07.002

[15] F. G. Mann and B. C. Saunders, Practical Organic Chemistry, 4th ed., New York: Longman, 1978.

[16] L. A. Petrov, Y. Alhamed, A. Al-zahrani and M. Daous, Role of chemical kinetics in the heterogeneous catalysis studies, Chinese Journal of Catalysis 32 (2011), 1085-1112. https://doi.org/10.1016/S1872-2067(10)60225-2 
[17] C. Perego and P. Villa, Catalyst preparation methods, Catalysis Today 34 (1997), 281305. https://doi.org/10.1016/S0920-5861(96)00055-7

[18] S. K. Saxena, N. Viswanadham and A. H. Al-Muhtaseb, Effect of zeolite pore morphology on solvent-less alkylation of benzene with 1-hexene, Materials Today Chemistry 4 (2017), 45-52. https://doi.org/10.1016/j.mtchem.2016.12.004

[19] F. Schuth and K. Unger, Precipitation and Co-precipitation, Handbook of Heterogeneous Catalysis 1 (1997), 13-18.

[20] G. V. Smith and F. Notheisz, Heterogeneous Catalysts in Organic Chemistry, Academic Press, 1999.

[21] K. T. Wan and M. E. Davis, Asymmetric synthesis of naproxen by a new heterogeneous catalyst, Journal of Catalysis 152 (1995), 25-30. https://doi.org/10.1006/jcat.1995.1056

[22] K. Wilson and J. H. Clark, Solid acids and their use as environmentally friendly catalysts in organic synthesis, Pure and Applied Chemistry 72(7) (2000), 1313-1319. https://doi.org/10.1351/pac200072071313

[23] Xing-Dong Yuan, J. N. Park, J. Wang, C. W. Lee and S. E. Park, Alkylation of benzene with 1-dodecene over USY zeolite catalyst: effect of pretreatment and reaction conditions, Korean Journal of Chemical Engineering 19(4) (2002), 607-610. https://doi.org/10.1007/BF02699304

[24] B. Zhang, Y. Ji, Z. Wang, Y. Liu, H. Sun, W. Yang and P. Wu, Liquid-phase alkylation of benzene with ethylene over postsynthesized MCM-56 analogues, Applied Catalysis A: General 443-444 (2012); 103-110. https://doi.org/10.1016/j.apcata.2012.07.028 